Life (Dis)satisfaction and the Decision to Migrate: Evidence from Central and Eastern Europe

Vladimir Otrachshenko Olga Popova

Working Paper n. 570

October 2012 


\title{
Life (Dis)satisfaction and the Decision to Migrate: Evidence from Central and Eastern Europe*
}

\author{
Vladimir Otrachshenko ${ }^{\dagger} \quad$ Olga Popova $^{\ddagger}$
}

\begin{abstract}
This paper provides empirical evidence of the impact of life satisfaction on the individual intention to migrate. The impacts of individual characteristics and of country macroeconomic variables on the intention to migrate are analyzed jointly. Differently from other studies, we allow for life satisfaction to serve as a mediator between macroeconomic variables and the intention to migrate. Using the Eurobarometer Survey for 27 Central Eastern European (CEE) and Western European (non-CEE) countries, we find that people have a higher intention to migrate when dissatisfied with life. The socio-economic variables and macroeconomic conditions have an effect on the intention to migrate indirectly through life satisfaction. The impact of life satisfaction on the intention to migrate for middle-aged individuals with past experience of migration, low level of education, and with a low or average income from urban areas is higher in CEE countries than in non-CEE countries.
\end{abstract}

Keywords: life satisfaction, migration, decision making JEL Classification: I31, J61

*This research was supported by the ERSTE Foundation Generations in Dialogue Fellowship for Social Researchers. We thank Alena Bičáková, David Blanchflower, Andrew Clark, Maria A. Cunha e Sá, Ira Gang, Jan Kmenta, Rainer Münz, Luis Catela Nunes, Andreas Ortmann, Andrew Oswald, Alexandre Sidorenko (in alphabetic order), ERSTE Foundation Fellows, and participants at 8th Demographic and Ageing Forum (St. Gallen), IV Joint IOS/APB Summer Academy on Central and Eastern Europe: Recent Challenges in Migration Research, Economic and Broader Development Issues (Tutzing), IZA Workshop on Sources of Welfare and Well-Being (Bonn), VII Summer School on International Migration: Challenges and Opportunities for the EU and Its Neighborhood (Florence), International Conference Market and Happiness: Do Economic Interactions Crowd Out Civic Virtues and Human Capabilities? (Milan), Synergizing Political Economy Research in Central and Eastern Europe Workshop (Budapest), Quantitative Economics Doctorate Jamboree (Lisbon) for valuable comments and helpful suggestions. All expressed opinions and remaining errors are those of the authors.

${ }^{\dagger}$ Nova School of Business and Economics, Lisbon, Portugal. E-mail: vladotr@fe.unl.pt. Address: Nova School of Business and Economics, Nova University of Lisbon, Campus de Campolide, 1099-032 Lisbon, Portugal.

${ }_{\ddagger}^{\ddagger}$ Institute for East and Southeast European Studies (IOS), Regensburg, Germany, and Center for Economic Research and Graduate Education, Charles University, and the Economics Institute of the Academy of Sciences of the Czech Republic (CERGE-EI), Prague, Czech Republic. E-mail: popova@ios-regensburg.de. Address: IOS Regensburg, Landshuter Str. 4, 93047 Regensburg, Germany. 


\section{Introduction}

The factors driving the individual decision to migrate such as job and educational opportunities, expected income, relative deprivation, a better provision of social benefits and public goods, etc., have been widely explored in the literature. ${ }^{1}$ However, nonpecuniary aspects also play a role in migration decisions (see Stark [54]). For instance, during conflict periods such as wars, terrorist attacks, and other regional instabilities, higher migration flows are observed regardless of any pecuniary aspects. ${ }^{2}$ Also, the quality of institutions such as civil liberties, political rights, protection of property rights, corruption, and the level of institutionalized democracies (e.g., dictatorship) cause migration flows even when monetary benefits are sufficiently high in the country of origin. ${ }^{3}$ As a result, these non-pecuniary aspects as well as tastes and culture, hidden reasons and motives such as a feeling of deserving a better life, and a feeling of fairness, affect the decision to migrate but may not be observed by a researcher. In this case a life satisfaction measure may be used as a proxy for both pecuniary and non-pecuniary aspects. ${ }^{4}$ In fact, many surveys include questions regarding life satisfaction, where individuals evaluate the overall quality of their own life, providing the information that can be used for those purposes.

In the literature, only a few studies have investigated the relationship between life satisfaction and individual decisions and activities. Examples of such studies are Antecol \& Cobb-Clark [4], Clark [17], Freeman [30], among others, who use job satisfaction as a predictor of future job quits. Lyubomirsky et al. [45] suggest that satisfied with life people are likely to be more successful and socially active, while Frey \& Stutzer [32] argue that people who are satisfied with life are more likely to decide to get married. Guven et al. [37] examine the effect of the gap in happiness between spouses on the probability to divorce. Besides the potential benefit of using the life satisfaction mea-

\footnotetext{
${ }^{1}$ See Berger \& Blomquist [5], Borjas[15], De Jong et al. [19], Dustmann [26], Gibson \& McKenzie [33], Greenwood [35], Kennan \& Walker [41], Stark [55], Stark \& Bloom [56], Stark \& Taylor [57], Stark \& Wang [58], Tiebout [60], among others.

${ }^{2}$ See Bohra-Mishra \& Massey [13], Dreher et al. [25], Morrison [47], Sirkeci [52], among others.

${ }^{3}$ See Bertocchi \& Strozzi [6] and [7], among others.

${ }^{4}$ See Lyubomirsky et al. [46] and De Neve et al. [21].
} 
sure in the analysis, the major cost is potential endogeneity. For instance, in a recent paper, Guven [36], using the instrumental variable approach to overcome endogeneity, claims that people who are satisfied with life spend less and save more.

Our paper contributes to the existing literature on migration and life satisfaction, and opens the discussion about the ability of using subjective indicators to capture different factors affecting the migration decision. Using the Eurobarometer survey for 27 Central Eastern (CEE) and Western European (non-CEE) countries in the period of 2008, we examine the impact of life satisfaction on the individual intention to migrate (hereafter, migration decision).$^{5}$

In our analysis, we distinguish three types of leaves: internal, temporary international, and permanent international leaves (hereafter, permanent and temporary migrations). Of particular interest is the impact of life satisfaction on individual permanent and temporary migration decisions. In order to explain the permanent and temporary migrations, we combine individual and country level variables that may affect the migration decision. Individual variables are represented by socio-economic characteristics such as age, income, education, and past experience of migration, while country level variables are unemployment, GDP per capita, inequality, and the quality of governance. Country level variables and socio-economic characteristics are allowed to affect the individual migration decision not only directly but also through life satisfaction. That is, differently from other studies, in this paper, life satisfaction plays the role of a mediator between country-wide economic and political conditions and the individual intention to migrate. The impacts of individual characteristics and of country macroeconomic variables on the decision to migrate are analyzed jointly.

The empirical findings indicate that people have a higher intention to migrate when dissatisfied with life. The results hold for all types of leaves: internal, temporary international, and permanent international. The socio-economic variables and macro-

\footnotetext{
${ }^{5}$ Central and Eastern European countries in our sample are Bulgaria, the Czech Republic, Estonia, Hungary, Latvia, Lithuania, Poland, Romania, Slovakia and Slovenia. Western European countries are Austria, Belgium, Cyprus (Republic), Denmark, Finland, France, Germany, Greece, Ireland, Italy, Luxembourg, Malta, Netherlands, Portugal, Spain, Sweden, and the United Kingdom.
} 
economic conditions have an effect on the intention to migrate indirectly through life satisfaction. We also find differences in migration decisions between the CEE and Western Europe. The impact of life satisfaction on the intention to migrate for middleaged individuals with past experience of migration, low level of education, and with a low or average income from urban areas is higher in CEE countries than in non-CEE countries. The empirical findings of this paper shed some light on how migration flows vary for different groups of individuals in those regions.

The rest of the paper is organized as follows. The next section briefly reviews the relevant literature. Then we present the empirical framework and robustness check, describe data, and discuss estimation results. The final section concludes.

\section{Literature Review}

The relationship between migration and life satisfaction has not yet been thoroughly examined in the economic literature. Existing studies at the individual level focus mostly on the life satisfaction of actual migrants and of their next generations. For instance, De Jong, Chamratrithirong, \& Tran [20] study the life satisfaction of migrants in Thailand and argue that life satisfaction typically decreases after moving to a different place, while Easterlin \& Zimmerman [29] argue that migrants from Eastern to Western Germany are relatively less satisfied than the locals living in the Western part. Safi [50] also suggests that immigrants in Europe and their generations are less satisfied than the natives.

At the country level, Blanchflower, Saleheen, \& Shadforth [9] and Blanchflower \& Shadforth [10] analyze the migration flows from Central and Eastern Europe. The authors find that the higher number of immigrants in the UK is from those CEE countries that have a lower GDP per capita and a lower average life satisfaction. Such pattern invites us to attempt to disentangle the effects of country level variables and life satisfaction on the migration decision in CEE and non-CEE countries.

In labor economics, the use of job satisfaction anchored to labor mobility has re- 
ceived substantial attention. Most studies in this stream of literature argue that job dissatisfaction is a strong predictor of job quit intentions as well as actual quits (see Antecol \& Cobb-Clark [4], Bockerman \& Ilmakunnas [11], Clark [17], Freeman [30], Shields \& Ward [51], Stevens [59], among others).

In a seminal study, Freeman [30] argues that the importance of satisfaction data for studying labor mobility is underestimated in the economic literature. The author suggests using individual satisfaction to evaluate the indirect effects of observed variables as well as a proxy for unobserved objective factors. For instance, job satisfaction may serve as an indicator of workplace quality. In line with this suggestion, Clark [17] points out that different job satisfaction domains, for instance, satisfaction with career opportunities, relations with supervisors, use of initiative, reflect unobservable job quality characteristics that can be used to measure the probability of job quits. Using data from BHPS, the author finds that dissatisfaction with payment, working hours, the type of work, job security, and the use of initiative are significant predictors of future actual job quits. Bockerman \& Ilmakunnas [11] analyze Finnish data and argue that job dissatisfaction as a proxy for adverse working conditions induces quit intentions and actual job quits. The topic of job satisfaction and quits in different contexts is further explored by Antecol \& Cobb-Clark [4] for military personnel, by Shields \& Ward [51] for nurses, and by Stevens [59] for academics. All these studies underline the role of dissatisfaction in labor mobility and provide a rationale for studying the implications of dissatisfaction and migration intention.

In our paper, we examine the individual intention to migrate, not the actual migration decision. The psychological theories of reasoned action and planned behavior suggest that the individual intention predicts the actual decision and behavior. ${ }^{6}$ As the predictions of these theories suggest, the better incorporation of individual (e.g., information, abilities, and emotions) and external (e.g., opportunity costs and external barriers for performing a behavior) factors into the model of hypothetical decisions re-

\footnotetext{
${ }^{6}$ See Ajzen \& Fishbein [3] for an extensive review of the psychological literature on intentions and actual behavior; see Rabinovich \& Webley [48] for the psychological factors affecting the realization of intentions into actual behavior.
} 
duces the gap between intended and actual behaviors (see Ajzen \& Fishbein [2], Ajzen [1], and Hale \& Householder [38]). Recently, in the context of a Prisoner's Dilemma game, Vlaev [61] argues that real and hypothetical decisions are different. However, a common critique to such findings is that they cannot be generalized to the whole population due to the use of students in the experiments. Also, the actual data may be too costly or rarely available to the researcher.

Data on individual intentions rather than actual labor mobility are also used in some economic studies (see Antecol \& Cobb-Clark [4], Kristensen \& Westergerd-Nielsen [42], Shields \& Ward [51], among others). In the context of migration, empirical evidence in favor of a strong link between the intended and actual decision is provided by Gordon \& Molho [34] and Boheim \& Taylor [12]. Gordon \& Molho [34] conclude that in the UK, a high share of people who intend to migrate actually moves within five years. Furthermore, Boheim \& Taylor [12] argue that the actual probability to move for potential migrants is three times higher than for those who do not intend to move. Therefore, the analysis of the individual intention to migrate is important for understanding the actual migration decision-making process.

\section{Methodology}

\subsection{The Model}

In this section we present the theoretical framework of the individual intention to migrate. An individual $i$ is faced with a choice between the following alternatives: stay in the home country (1), move to another country permanently (2), move to another country temporarily (3), and move within home country (4). Following Dolan \& Kahneman [24], we consider life satisfaction as a proxy to experienced utility. Using the additive random utility model for multiple alternatives as described by Cameron \& Trivedi [16], the individual utility associated with the $k^{\text {th }}$ alternative can be represented 
as follows:

$$
\begin{gathered}
U_{i k}=V_{i k}\left(\mathbf{x}_{i}, \mathbf{c}\right)+\varepsilon_{i k}, k=1, \ldots, 4 \\
V_{i k}\left(\mathbf{x}_{i}, \mathbf{c}\right)=\mathbf{x}_{i}^{\prime} \boldsymbol{\beta}_{\mathbf{k}}+\mathbf{c}^{\prime} \boldsymbol{\gamma}_{\mathbf{k}}
\end{gathered}
$$

where $U_{i k}$ represents the experienced utility of an individual $i$ in a destination $k . k$ represents four alternatives to migrate. $V_{i k}\left(\mathbf{x}_{i}, \mathbf{c}\right)$ represents the deterministic component of utility. In this study $V_{i k}\left(\mathbf{x}_{i}, \mathbf{c}\right)$ is measured by the life satisfaction score. $\varepsilon_{i k}$ is the random component of utility that stands for individual unobserved characteristics. $\mathbf{x}_{i}$ are individual $i$ characteristics such as income, level of education, employment and marital statuses, past experience of migration, age, and gender. c represents country characteristics, which may include the level of GDP, unemployment, income inequality. $\boldsymbol{\beta}_{\mathbf{k}}$ and $\boldsymbol{\gamma}_{\mathbf{k}}$ are the parameters of the model.

The individual decision to migrate is based on choosing the alternative with the highest utility. Even though there may be mental and material costs of the intention to migrate, without loss of generality, these costs are assumed to be zero. ${ }^{7}$

An individual $i$ decides to migrate from the home country to the destination $k$ if the utility after moving to the destination is higher than the one from staying in the home country and from all other destinations, $U_{i k} \geqslant U_{i h}$, all $k \neq h$. The alternative $h$ of staying in the home country is used as the reference alternative. Thus, the probability to migrate to the destination $k$ is expressed as follows:

$$
\begin{aligned}
\operatorname{Pr}\left[\text { MigrDecision }_{i}\right. & =k]=\operatorname{Pr}\left[U_{i k} \geqslant U_{i h}, \text { all } k \neq h\right]= \\
& =\operatorname{Pr}\left[V_{i k}\left(\mathbf{x}_{i}, \mathbf{c}\right)+\varepsilon_{i k} \geqslant V_{i h}\left(\mathbf{x}_{i}, \mathbf{c}\right)+\varepsilon_{i h}, \text { all } k \neq h\right]= \\
& =\operatorname{Pr}\left[\varepsilon_{i h}-\varepsilon_{i k} \leqslant V_{i k}\left(\mathbf{x}_{i}, \mathbf{c}\right)-V_{i h}\left(\mathbf{x}_{i}, \mathbf{c}\right), \text { all } k \neq h\right]
\end{aligned}
$$

The errors $\varepsilon_{i k}$ are assumed to be i.i.d. type 1 extreme value, with density function

$$
f\left(\varepsilon_{i k}\right)=e^{-\varepsilon_{i k}} \exp \left(-e^{-\varepsilon_{i k}}\right), \quad k=1, . ., 4 .
$$

\footnotetext{
${ }^{7}$ In a seminal study Sjaastad [53] distinguishes between monetary and non-monetary costs of migration. However, we do not have this information in our data.
} 
Given equations (2) and (3), we result in a multinomial logit model

$$
\operatorname{Pr}\left[\text { MigrDecision }_{i}=k\right]=\frac{e^{V_{i k}}}{e^{V_{i 1}}+e^{V_{i 2}}+e^{V_{i 3}}+e^{V_{i 4}}} .
$$

Given equation (1b), the probability of the decision to migrate from the home country to the destination $k$ depends negatively on the utility of living in the home country. ${ }^{8}$ Since life satisfaction in the destination is not available, $V_{i k}\left(x_{i}, c\right)$, without loss of generality, we assume that it is constant for each destination. ${ }^{9}$ This assumption can be relaxed in future research.

In our empirical specification, we follow a two-level regression analysis. This type of analysis allows us to relate and structure the characteristics of individuals and countries in one framework. ${ }^{10}$ As can be observed from Figure 1 in the appendix, there are two levels, namely, between (country) and within (individual) levels. At the between level in the rectangle, country political and economic variables such as GDP per capita, unemployment, inequality and others are included. At the within level, individual variables appear in the rectangles such as individual socio-economic characteristics and the variable that represents the individual intention to migrate. The dasheddotted arrow from life satisfaction to the intention to migrate hypothesizes the causal effect. Even though the variable of interest is the intention to migrate, not the actual decision, there may be the potential endogeneity issue related to simultaneity. This issue is discussed in the next section.

The econometric model can be expressed as follows: equations (5a) and (5b1-5b3) are attributed to the within level, while equations (6a1-6a2) and (6b1-6b3) represent the between level.

\footnotetext{
${ }^{8}$ Alternatively, the difference $V_{i k}\left(\mathbf{x}_{i}, \mathbf{c}\right)-V_{i h}\left(\mathbf{x}_{i}, \mathbf{c}\right)$ has to affect the individual decision to migrate positively.

${ }^{9}$ One way to relax this assumption is to use the average life satisfaction in the country of destination. However, the individuals in our sample point out several destinations.

${ }^{10}$ Alternatively, a two-level hierarchical model with random intercepts can be estimated as described by Raudenbush \& Bryk [49]. However, due to the identification issue of the model, we estimate it sequentially. The results of both approaches are similar with only a difference in the efficiency of estimators.
} 


$$
\begin{aligned}
& \operatorname{Pr}\left(\text { MigrDecision }_{i}=k\right)=F\left(\beta_{0 k}+\beta_{1 k} \text { LifeSat }_{i}+\beta_{2 k} \text { LifeSat }_{i}+\right. \\
& \left.+\beta_{3 k} \text { LifeSat4 }_{i}+\beta_{4 k} \text { Econd }_{i}+\boldsymbol{\eta}_{\mathbf{k}} \mathbf{x}_{\mathbf{i}}+\theta_{k, s}+\varepsilon_{i k}\right) \\
& \text { LifeSat }_{i}^{*}=\mu_{0 j}+\boldsymbol{\mu}_{\mathbf{j}} \mathbf{x}_{\mathbf{i}}+\lambda_{j, s}+\epsilon_{i j}, j=2,3,4 \\
& \theta_{k, s}=\gamma_{0 k}+\gamma_{1 k} \text { Politics }+\gamma_{2 k} \text { Economics }+\gamma_{3 k} C E E+u_{k} \\
& \lambda_{j, s}=\pi_{0 j}+\pi_{1 j} \text { Politics }+\pi_{2 j} \text { Economics }+\pi_{3 j} C E E+\zeta_{j},
\end{aligned}
$$

where the subscript $i$ stands for individual. The variable Migr Decision $_{i}$ represents an individual decision to participate in the $k^{\text {th }}$ alternative to leave, $k=2,3,4$, that is permanent international $(\mathrm{k}=2)$, temporary international $(\mathrm{k}=3)$, and internal leaves $(\mathrm{k}=4)$. The intention to stay in the home country $(\mathrm{k}=1)$ is used as the reference alternative. LifeSat is an individual's self-reported satisfaction with life in the home country; Econd ${ }_{i}$ is a dummy variable, which is equal to one if the decision to migrate is driven by economic factors such as higher expected income, better working and housing conditions and zero if the factors are non-economic, for instance, moving closer to family or friends, or expecting a better local environment, among others. Even though some individuals answered that they do not have the intention to migrate, they also provided the possible reason. ${ }^{11} \mathbf{x}_{i}$ includes individual socio-economic characteristics, namely, age, gender, marital status, children, income, level of education, employment status, living in an urban area, and past migration experience. $\theta_{k, s}$ and $\lambda_{j, s}$ are country fixed effects that account for the average country-specific life satisfaction and the propensity to migrate. Politics and Economics are the sets of country-level political and economic variables such as GDP per capita, the unemployment rate, and the Gini coefficient. Also, we introduce a dummy variable, $C E E$, that is equal to one if home country is in Central and Eastern Europe and zero otherwise. These variables correspond to $\mathbf{c}$ in the theoretical model. $\theta_{k}$ and $\lambda_{j}$ are mean country-specific intercepts, while $\varepsilon_{i k}, \epsilon_{i k}, u_{k}$ and $\zeta_{j}$ are stochastic disturbances.

\footnotetext{
${ }^{11}$ The exact question is "Regardless of whether you might move to another country or not, which of the following might encourage you to move to another country?"
} 
The responses to life satisfaction questions are categorically ordered and take values from one to four in a Likert scale. To evaluate the effects of each level of life satisfaction on individual migration decision separately, we separate LifeSat ${ }_{i}$ into four dummy variables and use the lowest level of life satisfaction as a base category in our estimations.

$$
\text { LifeSat }_{i}=1 \text {, if LifeSat } i=j \text { and } 0 \text { otherwise, } j=1, \ldots, 4
$$

The reliability of subjective data is of potential concern. However, as summarized by Frey \& Stutzer [31] from the economic, sociological, and psychological literature, life satisfaction data are valid, consistent and reliable measures of individual well-being. That is, people are able to evaluate own quality of life without systematic errors. Moreover, life satisfaction is relatively stable over time. ${ }^{12}$

To analyze the determinants of the individual migration decision, the within level equations (5a) and (5b1-5b3) are estimated by using the maximum likelihood estimation (MLE). By estimating equation (5a) using a multinomial logit model, we examine the direct impact of life satisfaction and individual socio-economic characteristics on the probability to migrate abroad permanently, temporarily, or within a country against the reference category of no leave. To analyze the determinants of life satisfaction at each level, the equations (5b1-5b3) are estimated by logit.

The estimates of country dummy variables from equation (5a) are taken as dependent variables for equations (6a1-6a2). These estimates represent the country fixed effects. We assume that country level political and economic variables affect the decision to migrate abroad permanently and temporarily and have no effect on the decision to migrate internally. The decision to migrate internally is likely to be affected by regional level political and economic variables that are difficult to incorporate. Therefore, the mean country-specific intercept of the permanent migration decision and the temporary migration decision are included into the between level, while the intercept of

\footnotetext{
${ }^{12}$ See psychological and economic studies on the set point theory of life satisfasction (Clark et al. [18]; Di Tella et al. [22]; Diener et al. [23]; Lucas et al. [43] and [44], among others).
} 
internal migration is not.

The values for the dependent variables of equations (6b1-6b3) are the estimates of country dummies from equations (5b1-5b3). The dependent variables of these equations represent the average value of being satisfied in a particular country at the satisfaction levels 2,3 , and 4, respectively. The equations (6a1-6a2) and (6b1-6b3) are estimated by ordinary least squares and allow us to analyze the effects of country level political and economic variables directly on the permanent migration decision and on life satisfaction. Since equations (5a), (5b1-5b3) at within (the individual level) and (6a1-6a2), (6b16b3) at between (the macro level) levels are estimated sequentially, we bootstrap the standard errors and cluster them at the country level.

\subsection{Robustness Check}

The econometric model presented above may be subject to several potential caveats. First, even though the use of data on the individuals who intend to migrate instead of those who actually migrate helps to circumvent a positive selection bias, the simultaneity bias in the estimates of the effect of life satisfaction on the decision to migrate is still a potential concern. Some unobserved individual characteristics such as restlessness, perfectionism, or ambition, may make people both dissatisfied with life and be prone to migration. However, these concerns of a potential simultaneity bias are common for all cross-sectional studies on satisfaction and quitting behavior, for instance, Antecol \& Cobb-Clark [4] and Bockerman \& Ilmakunnas [11], among others.

Second, the small number of individuals for each type of migration in our sample may produce non-robust estimation results, both at individual and country levels. Finally, there may be the cross-country differences in the life satisfaction measure.

In order to respond to these potential concerns, we redefine the intention to migrate into a binary variable, which is equal to one if an individual intends to migrate permanently, temporarily, or internally, and zero otherwise. Thus, those who intend to migrate are treated in the estimation together regardless of the type of potential migra- 
tion. To address the simultaneity issue, equations related to the intention to migrate and to four levels of life satisfaction are estimated simultaneously by using a multivariate probit.In addition, we estimate a SUR model with the intention to migrate and life satisfaction equations, where life satisfaction is treated as a continuous variable. In both models, the correlation of residuals between any level of life satisfaction and the intention to migrate is not statistically significant. ${ }^{13}$ These results suggest that there is no endogeneity problem.

Since the life satisfaction variable is categorically ordered and measured in a Likert scale, this variable can be represented as follows:

$$
\text { LifeSat }_{i}= \begin{cases}4 & \text { if } \tau_{3}<\text { LifeSat }_{i}^{*} \\ 3 & \text { if } \tau_{2}<\text { LifeSat }_{i}^{*}<\tau_{3} \\ 2 & \text { if } \tau_{1}<\text { LifeSat }_{i}^{*}<\tau_{2} \\ 1 & \text { if } \text { LifeSat }_{\mathbf{i}}^{*}<\tau_{1}\end{cases}
$$

where $\tau_{j}$ represents the threshold of switching from category $j-1$ to category $j$, for $j=\overline{1,4}$, and LifeSat $t_{i}^{*}$ represents the corresponding unobserved life satisfaction.

In order to obtain the unobserved life satisfaction of individuals, we follow the latent variable approach described by Bollen [14]. The latent variable, LifeSat*, is not observed but is inferred from the responses to the question regarding life satisfaction, according to the following measurement equation:

$$
\text { LifeSat }{ }_{i}^{*}=\boldsymbol{\mu} \mathbf{x}_{i}+\lambda_{s}+\Lambda \nu_{i}
$$

where LifeSat $t_{i}^{*}$ is a continuous latent life satisfaction variable, $\mathbf{x}_{\mathbf{i}}$ are observed individual socio-economic characteristics, $\lambda_{s}$ are country fixed effects, and $\Lambda$ is a factor loading. $\nu_{i}$ is a measurement error that follows a logistic distribution.

The continuous representation of life satisfaction allows us to take into account the cross-country differences in life satisfaction. Also, it helps to avoid the equi-distance problem. That is, the difference between 1 and 2 in a Likert scale in life satisfaction may

\footnotetext{
${ }^{13}$ The estimation results are available upon request.
} 
not have the same impact on the intention to migrate as the difference between 3 and 4. Then, we introduce the unobserved continuous life satisfaction into the migration equation as follows:

$$
\operatorname{Pr}\left(\text { MigrDecision }_{i}=1\right)=F\left(\beta_{0}+\beta_{1} \text { LifeSat }_{i}^{*}+\beta_{2} \text { Econd }_{i}+\boldsymbol{\eta} \mathbf{x}_{i}+\boldsymbol{\theta C D}+\varepsilon_{i}\right)
$$

where $\varepsilon_{i}$ is the stochastic disturbance and follows a logistic distribution. The other coefficients and explanatory variables are interpreted in the same manner as in the previous section. Then, equations from (7) to (9) are estimated simultaneously using the robust maximum likelihood. After estimating the individual level, we proceed to the country level estimation. This estimation is similar to the one described in previous section.

\section{Data}

The primary data source for examining the model described above is the Eurobarometer survey in 2008. This is a cross-sectional survey based on nationally representative samples that include randomly selected respondents from 27 European countries, out of which 10 are Central and Eastern European countries. ${ }^{14}$ There are about 1000 respondents per country. The survey contains questions on individual values and attitudes towards life, previous migration experience, the intentions to migrate in the future, and individual socio-economic characteristics. Since the survey has no questions on respondent's income, we use a proxy for income, namely, the judgement regarding the financial situation of the respondent's household. The question that we use is "How would you judge the financial situation of your household? Very good (4), rather good (3), rather bad (2), very bad (1)."

The question on life satisfaction that we use is "On the whole, are you very satisfied (4), fairly satisfied (3), not very satisfied (2) or not at all satisfied (1) with the life you

\footnotetext{
${ }^{14}$ The list of countries in our sample is Austria, Belgium, Bulgaria, Cyprus (Republic), the Czech Republic, Denmark, Estonia, Finland, France, Germany, Greece, Hungary, Ireland, Italy, Latvia, Lithuania, Luxembourg, Malta, the Netherlands, Poland, Portugal, Romania, Slovakia, Slovenia, Spain, Sweden, and the United Kingdom. 
lead?". The mean life satisfaction scores for two waves of the Eurobarometer survey are presented in Table 1 in the appendix. As observed, there are two columns that correspond to waves of April-May 2008 and October-November 2008. In our study, we use only the wave of October-November 2008, since this is the only wave that contains information on both life satisfaction and migration. The highest mean life satisfaction in our sample is in Denmark, while the lowest is in Bulgaria. People from Central and Eastern Europe report lower levels of life satisfaction than people from Western European countries. This ranking is consistent with the similar ones from other databases, e.g. World Values Survey. One may be concerned that the period used for the analysis coincides with the economic crisis. However, as observed from Table 1, there are no major changes in the average life satisfaction before and during the crisis. Moreover, small changes in the average life satisfaction observed in some countries can be attributed to psychological aspects of individuals such as the fear of losing a job.

Survey questions about intended migration used in this research are presented in Figure 2 in the appendix. The following three questions are used to construct the variable of interest MigrDecision, , namely "Do you intend to move in the next five years?"; "Do you intend to move within country or to another country?"; and "How long do you expect to stay abroad?" As mentioned above, we distinguish three types of leaves: permanent international, temporary international, and internal. If an individual responds that he/she intends to move in the next five years within country, we consider such a response as the intention to migrate internally. If an individual responds that he/she intends to move in the next five years to another country for a few weeks, few months, few years, or for more than a few years but not indefinitely, we consider such a response as the intention to migrate abroad temporarily. Finally, if an individual responds that he/she intends to move in the next five years to another country for the rest of his/her life, we consider such a response as the intention to migrate abroad permanently.

Descriptive statistics for the questions on life satisfaction and intended leaves are 
presented in Table 2 in the appendix. The number of intended migrants for all types of leaves is about 10 percent of our sample. Thus, for some countries, we may have only a few intended migrants. However, this should not change the main conclusions of our paper.

The country level data, namely, the real GDP per capita, unemployment rates, and Gini coefficients are obtained from the Eurostat database. We also use the Worldwide Governance Indicators (see Kaufmann, Kraay, \& Mastruzzi [40]). The correlation matrix for the macroeconomic variables is presented in Table 3.

\section{$5 \quad$ Results and Discussion}

\subsection{Individual Level Effects}

In this section we present and discuss the results for the decisions to migrate permanently, temporarily, and internally. To understand the migration decision at each level of life satisfaction, life satisfaction in our estimation is represented by three dummy variables, where the default group corresponds to individuals that indicate the lowest level of life satisfaction.

Individual level estimation results for the decision to migrate and life satisfaction are obtained by estimating equations (5a) and (5b1-5b3) and presented in Tables 4 and 5 in the appendix, respectively. In Table 4, the columns correspond to the particular intention to migrate, namely permanent, temporary, and internal. As observed, different levels of life satisfaction have strong negative impact on each type of the intention to migrate. This means that individuals with higher levels of life satisfaction have a lower intention to migrate. We also find that different levels of life satisfaction are jointly statistically significant for all types of migration intentions (for instance, in the equation for the intention to migrate permanently, the Lagrange multiplier test $\left.(\mathrm{LM})=41.11^{* * *}\right){ }^{15}$ Also, the impact of being at satisfaction level 2, "not very satisfied", is different from the impacts of satisfaction levels 3, "fairly satisfied", and 4, "very

\footnotetext{
$15 * * *, * *, *$ stand for 1,5, and 10 percent significance levels, respectively.
} 
satisfied" (in the equation for the intention to migrate permanently, LM=32.48*** and $\mathrm{LM}=12.58^{* * *}$, respectively). These results suggest that it is important to consider life satisfaction at different levels.

In Table 4, we also observe that older, married, with a child, without past experience of migration, and employed individuals have a lower intention to migrate, while the self-employed, from an urban area, and those for whom the decision to migrate is driven by economic factors have a higher intention to migrate.

In Table 5, the results for the within level (individual) for each level of life satisfaction are presented. Life satisfaction is higher for married, with higher income and education, and employed or self-employed individuals and is U-shaped in age (see column "very satisfied"). These results support the findings from the existing happiness literature. The effects of all variables in Table 5 represent mediating relationships with the intentions to migrate. Interestingly enough, even though in our sample we do not find the effect of income on migration intentions (see Table 4), this effect is mediated by life satisfaction (see Table 5). ${ }^{16}$ Thus, empirical findings suggest that even though the direct effect may not be observed, the relationship may be established through life satisfaction.

Since our dependent variable, the intention to migrate, is nominal, we have computed the average marginal effects for the explanatory variables from equation (5a). ${ }^{17}$ These effects are presented in Table 6A. As observed from this table, an increase in life satisfaction may lead to the increase in the probability to stay in the country of residence. In particular, as compared to individuals with satisfaction level 1, "not at all satisfied", individuals with satisfaction level 3, "fairly satisfied", and 4, "very satisfied", are more likely to stay by $5.95 \%$ and $6.49 \%$, respectively. The average marginal effects of life satisfaction on the intention to migrate for different groups of individuals are discussed in details in Section 5.3. However, since the countries in our sample have different levels of economic development, there may be important cross-country factors

\footnotetext{
${ }^{16}$ We also estimated equation (5a) without the life satisfaction variable, but we do not find evidence that income affects the intention to migrate either.

${ }^{17}$ In our explanations, we multiply the calculated marginal effects by 100 .
} 
that may affect the individual decision to migrate. This issue is explored in the next section.

\subsection{Country Level Effects}

The migration literature has emphasized the influence of economic and political conditions on the individual migration decision. ${ }^{18}$ In this paper, we also examine the relationship between the intention to migrate permanently and temporarily and various country characteristics. Differently from other studies, we use life satisfaction as a mediator between the macroeconomic variables and the intention to migrate. Due to high correlations between macroeconomic variables, we select only the logarithm of real GDP per capita, the unemployment rate, and the Gini coefficient as explanatory variables for equations (6a1-6a2) and (6b1-6b3) (see Table 3).

We are also interested in analyzing the country level differences in migration intentions between CEE and non-CEE countries. However, as can be observed from Table 3, there is a strong negative correlation between the logarithm of real GDP per capita and a dummy for CEE countries. Thus, we use these variables in different model specifications.

The results for the model with the logarithm of real GDP per capita and for the model with CEE are presented in Tables 7A and 7B, respectively. We have also estimated equations (6a1-6a2) with government effectiveness and other economic variables from Table 3. The results are robust to the choice of explanatory variables. ${ }^{19}$

In Tables 7A and 7B, the columns labeled as "INTERCEPT PERMANENT" and "INTERCEPT TEMPORARY" correspond to equations (6a1-6a2) for the intentions to migrate permanently and temporarily at the country level. ${ }^{20}$ As observed from these columns, none of the macroeconomic variables are statistically significant. ${ }^{21}$ Thus, we

\footnotetext{
${ }^{18}$ See Bertocchi \& Strozzi [6] and [7], Borjas [15], Dustmann, Fabbri, \& Preston [27], Dustmann, Hatton, \& Preston [28], Greenwood [35], Stark [55], Tiebout [60], among others.

${ }^{19}$ The results are available upon request.

${ }^{20} \mathrm{We}$ assume that country level political and economic variables have no effect on the decisions to migrate internally.

${ }^{21}$ We also estimated equation (5a) without the life satisfaction variable, but we do not find evidence that macroeconomic variables affect the intention to migrate either. 
do not have evidence that the logarithm of real GDP per capita, the unemployment rate, the Gini coefficient, and CEE variable affect the intention migrate permanently or temporarily directly. However, we find that these macroeconomic variables affect life satisfaction (see the columns "INTERCEPT LIFE SATISFACTION=2, 3, and 4"). In particular, the fraction of individuals "not very satisfied" (satisfaction level 2) decreases if GDP per capita increases (or a country belongs to the non-CEE region) and increases if the inequality among individuals rises, while the fraction of "very satisfied" individuals (satisfaction level 4) increases with higher GDP per capita (or the non-CEE region), lower unemployment, and lower inequality among individuals. As a result, we may conclude that the intention to migrate is affected by these macroeconomic variables through life satisfaction.

As mentioned above, some macroeconomic variables are highly correlated. In our case, government effectiveness, control of corruption and GDP per capita have a similar effect on life satisfaction and can be used indifferently. This is especially relevant for explaining the differences in migration intentions between CEE and non-CEE countries since governance conditions in these two regions are substantially different. For instance, according to the Worldwide Governance Indicators (see Kaufmann et al.[40]), the gap between government effectiveness and the control of corruption in these two regions is large (0.68 vs. 1.40 for government effectiveness and 0.37 vs. 1.51 for the control of corruption). According to Kaufmann et al. [40], the government effectiveness indicator measures the perceptions over the quality of public services provision and policy implementation, while the control of corruption measures the perceptions over the use of public power for private interests and the extent of state capture. All the relationships between country level life satisfaction, macroeconomic and governance variables have an expected sign and underline the importance of the improvement of economic and political conditions for individual satisfaction with life. As a result of improvements in economic development and control of corruption and governance, individuals intend to migrate less.

To check the robustness of our results, we redefine the migration decision variable 
into a binary variable and treat life satisfaction as a continuous latent variable. The individual level results are presented in Table 8. As observed from this table, the results from the modified equations support our previous findings. Also, findings are similar at the country level for unemployment and the Gini coefficients (see Tables 9A and 9B). However, we find that the logarithm of real GDP per capita affects both the intention to migrate and life satisfaction positively, while a CEE dummy affects them negatively. This finding can be explained by differences in institutional quality between $\mathrm{CEE}$ and non-CEE countries. For a given income at the individual level, people from CEE and non-CEE still have different opportunities to migrate. For instance, in 2008, nationals from CEE countries were still required to have a work permit to have a job in non-CEE and US labor markets. Overall, our findings highlight the importance of life satisfaction not only as a predictor of intentions to migrate, but also as a mediator between economic and political conditions and tho se intentions.

\subsection{Migration Decisions in CEE and Non-CEE Countries}

In this section we discuss the individual level differences in intentions to migrate permanently and temporarily from CEE and non-CEE countries. ${ }^{22}$ We examine the impact of life satisfaction on the individual intention to migrate for different groups of individuals.

To highlight that life satisfaction and expected income have separate effects on the individual migration decision, we consider those individuals who had the experience of a long-term migration in the past but still intend to migrate, hereafter movers. ${ }^{23}$ The average life satisfaction of these individuals in CEE countries is 2.39, while in non-CEE countries is 2.88. Individuals who did not migrate in the past and do not intend to migrate in the future, hereafter stayers, are used as a reference category. The average life satisfaction of stayers in CEE and non-CEE countries is 2.63 and 3.04, respectively.

\footnotetext{
${ }^{22}$ Since we study the impact of cross-country differences on the individual migration decision, we do not discuss the differences in decisions to migrate internally between individuals from CEE and non-CEE countries.

${ }^{23}$ We are grateful to David Blanchflower for this point.
} 
Comparing the average life satisfaction scores for movers and stayers, we find that movers have lower life satisfaction scores than stayers in the same region. Considering the responses of these individuals regarding the judgement of their households' current financial situation, we find that the average score for the financial situation for movers and stayers in CEE countries is very similar (2.42 vs 2.45). Therefore, we may conclude that movers in CEE countries met their income expectations by migrating, but they are still not satisfied with the quality of their own lives and, as a result, life dissatisfaction may drive them to migrate again. However, this effect is ambiguous in non-CEE countries. Even though the life satisfaction of movers from non-CEE is lower than the life satisfaction of stayers in this region (2.88 vs. 3.04), their judgement of their own financial situation is slightly different (2.68 for movers and 2.75 for stayers). Therefore, it might be the case that movers in non-CEE countries did not meet their income expectations and were not satisfied with the quality of their own lives. As a result, it is less clear whether the income or the life satisfaction effect dominates in the intention to migrate for individuals from the non-CEE region.

It should be noted that the results presented in this section are always in comparison with the reference group that represents "not at all satisfied" individuals. Comparing the average marginal effects for $\mathrm{CEE}$ and non-CEE countries in Table 6B, we observe that with an increase in life satisfaction the probability to migrate permanently and temporarily decreases more for individuals from non-CEE than from CEE. For instance, the probability of the intention to migrate permanently of "very satisfied" individuals is lower in comparison with that of "not at all satisfied" by $2.22 \%$ and $1.23 \%$ (by $1.73 \%$ and $2.16 \%$ in the case of temporary migration) in non-CEE and CEE countries, respectively. In other words, if the life satisfaction of individuals increases by the same amount in both regions, the individuals from CEE intend to migrate more. This result is in line with the widely documented differences in social and economic conditions in East European compared to Western countries. Thus, policies regulating migration flows from CEE countries should not be taken independently from improvements to well-being in the region. 
In Table 6B, we compute the average marginal effects of life satisfaction on the intention to migrate for each level of income, employment status, education, age, past experience of migration, and regional location of CEE and non-CEE individuals. As observed, if life satisfaction increases, non-CEE individuals intend to migrate less than CEE individuals at each level of income. For instance, the probability to migrate permanently for "very satisfied" individuals with income level 4 is lower by $2.49 \%$ and $1.42 \%$ (by $1.69 \%$ and $2.11 \%$ in the case of temporary migration) in non-CEE and CEE countries, respectively. The intuition behind this result is based on different income and employment prospects for people from CEE and non-CEE countries. According to data from the Eurostat, the average net nominal monthly earnings in non-CEE countries is about 1600EUR, while in CEE countries is 460EUR. At the same time, the average long-term unemployment rate is about $2 \%$ of the active population in non-CEE and 3\% in CEE countries. Given huge wage differentials and higher unemployment rate in the CEE region, individuals from this region are more likely to migrate to find a job abroad.

The results are further compared between the individuals with and without past migration experience. In non-CEE countries, "very satisfied" individuals with past migration experience have lower intentions to migrate permanently than "not at all satisfied" by $5.16 \%$, while in CEE countries, these individuals intend to migrate less by $3.22 \%$. Thus, once an individual migrated and met his/her expectations regarding life satisfaction, he/she intends to migrate less.

We also find that as compared to "not at all satisfied", the "fairly satisfied" and "very satisfied" self-employed individuals from non-CEE countries have a lower intention to migrate permanently than those from CEE, by $3.67 \%$ and $3.94 \%$ and by $2.12 \%$ and $2.27 \%$ (by $2.43 \%$ and $2 \%$ and by $2.9 \%$ and $2.53 \%$ in the case of temporary migration), respectively. In fact, the average life satisfaction of self-employed individuals in CEE countries is 2.78, while in non-CEE countries is 3.05. This difference is likely to be due to the lower quality of institutions in the CEE region. According to the Worldwide Governance Indicators (see Kaufmann et al.[40]), CEE countries underperform 
non-CEE countries in regulatory quality and rule of law, which is measured by the perceptions of regulations that allow and promote private sector development, degree of enforcement of property rights, the quality of the police, and the courts (0.99 vs. 1.42 and 0.63 vs. 1.46, respectively). Therefore, the life satisfaction of self-employed individuals may convey information about the quality of the business environment in the country where they work.

A similar pattern is observed for the "fairly satisfied" and "very satisfied" employed individuals; the probability to migrate permanently is lower by $1.95 \%$ and $2.09 \%$ for the non-CEE individuals and by $1.07 \%$ and $1.14 \%$ for the CEE ones (by $2.09 \%$ and $1.76 \%$ and by $2.45 \%$ and $2.17 \%$ in the case of temporary migration). For the "fairly satisfied" and "very satisfied" individuals who are not employed, we find that the intention to migrate is lower in non-CEE countries than in CEE, by $2.08 \%$ and $2.21 \%$ and by $1.16 \%$ and $1.24 \%$ (by $2.01 \%$ and $1.67 \%$ and by $2.42 \%$ and $2.12 \%$ in the case of temporary migration), respectively. ${ }^{24}$ These results suggest that individuals have lower intentions to migrate from regions where the social benefits are higher, which are consistent with the findings of previous literature (see Borjas [15]). For instance, according to data from the Eurostat, the average monthly unemployment benefit in non-CEE countries is about 370EUR, while in CEE countries, it is about 70EUR. Thus, the higher intentions to migrate from CEE of those who are not employed may reflect their dissatisfaction with the social security system. This point also finds support in the migration intention of individuals with different levels of education. We find that as compared to the "not at all satisfied" from the same region, the "very satisfied", individuals with less than 15 years of education in CEE countries have a lower intention to migrate by $1.04 \%$, while in non-CEE countries this difference is $1.92 \%$. Higher educated individuals at all levels of life satisfaction have lower intentions to migrate than the lower educated although they are still more likely to migrate from CEE countries.

Differences in the quality of the social security system and the quality of institutions

\footnotetext{
${ }^{24}$ In Table 6B, those who are not employed are denoted as "Not Working". This group of individuals consists of the unemployed, retired, and housekeepers.
} 
may also be reflected in the migration intentions of individuals at different ages. In Table 6B, we also split the results for the individuals in five age groups: 20, 30, 40, 50 , and 60 years old. We find that at all levels of life satisfaction migration intentions decrease with age. The highest difference between CEE and non-CEE countries in the intention to migrate permanently is observed for the age group of 30-year old. In CEE countries, where the quality of institutions and opportunities is lower, 30-year old "very satisfied" individuals intend to migrate by less $1.71 \%$, while in non-CEE countries, "very satisfied" individuals of the same age group intend to migrate by less $3.10 \%$.

Finally, we compare the average marginal effects of being a "not at all satisfied" individual with a "very satisfied" one from rural and urban areas in Table 6B. We observe that the probabilities of the intention to migrate permanently and temporarily from urban areas decrease by $1.38 \%$ and $2.49 \%$ in CEE countries and by $2.38 \%$ and $1.89 \%$ in non-CEE countries, respectively. Thus, dissatisfied individuals are likely to migrate more from urban areas in CEE, where they have more opportunities and better access to information to migrate abroad.

As our results suggest, the impact of life satisfaction on the intention to migrate for different groups of individuals in CEE is higher than in non-CEE countries. As discussed above, the life satisfaction measure may convey useful information regarding the quality of institutions and the business environment, the employment situation, and the development of a social security system in a region.

\section{Conclusion}

This paper provides empirical evidence of the impact of life satisfaction on the individual intention to migrate. The effects of both individual and country level factors on the intention to migrate are analyzed jointly. The empirical findings of this paper suggest that people dissatisfied with life have a higher intention to migrate. The individual socio-economic factors and macroeconomic conditions have an effect on the intention 
to migrate indirectly through life satisfaction. These empirical findings underline the importance of individual life satisfaction not only as a strong predictor of the individual migration decision, but also as a mediator between individual socio-economic variables and macroeconomic conditions and this decision.

Additionally, we analyze the differences in intentions to migrate permanently and temporarily for the Central Eastern European (CEE) countries and the Western European (non-CEE) countries. The impact of life satisfaction on the intention to migrate from CEE and non-CEE countries is examined for different groups of individuals. We find that at all levels of life satisfaction individuals with similar characteristics have higher intentions to migrate from CEE countries than from non-CEE countries. The low level of life satisfaction of individuals from CEE countries may be associated with the lower quality of institutions and business environment and with the development of the social security system in this region. Improvements in these conditions will result in an increase in individual life satisfaction and, thus, will lower individual migration intentions.

Our findings can be generalized to the migration decisions in regions with conflicts or natural disasters, with a low quality of institutions, and with economic crises. It may also be interesting to apply our model to study more in detail internal migration. This will be left for future research. 


\section{References}

[1] Ajzen, I. (1991): "The Theory of Planned Behavior", Organizational Behavior and Human Decision Processes, 50, 179-211.

[2] Ajzen, I., and M. Fishbein (1975): "Belief, Attitude, Intention, and Behavior: An Introduction to Theory and Research", Reading, MA: Addison-Wesley.

[3] Ajzen, I., and M. Fishbein (2005): "The Influence of Attitudes on Behavior". In D. Albarracin, B. Johnson, and M. Zanna (Eds.), The Handbook of Attitudes, Mahwah, NJ: Erlbaum, 173-221.

[4] Antecol, H., and D. Cobb-Clark (2009): "Racial Harassment, Job Satisfaction, and Intentions to Remain in the Military", Journal of Population Economics, 22, 713-738.

[5] Berger, M., and G. Blomquist (1992): "Mobility and Destination in Migration Decisions: The Roles of Earnings, Quality of Life, and Housing Prices", Journal of Housing Economics, 2(1), 37-59.

[6] Bertocchi, G., and C. Strozzi (2006): "The Age of Mass Migration: Economic and Institutional Determinants", IZA Discussion Paper No.2499.

[7] Bertocchi, G., and C. Strozzi (2008): "International Migration and the Role of Institutions", Public Choice, 137, 81-102.

[8] Blanchflower, D., and R. Freeman (1997): "The Attitudinal Legacy of Communist Labor Relations", Industrial and Labor Relations Review, 50(3), 438-459.

[9] Blanchflower, D., J. Saleheen, and C. Shadforth (2007): " The Impact of the Recent Migration from Eastern Europe on the UK Economy", Bank of England External MPC Unit Discussion Paper, No. 17.

[10] Blanchflower, D., and C. Shadforth (2009): "Fear, Unemployment and Migration", Economic Journal, 119, 136-182.

[11] Bockerman, P., and P. Ilmakunnas (2009): "Job Disamenities, Job Satisfaction, Quit Intentions, and Actual Separations: Putting the Pieces Together", Industrial Relations, 48(1), 73-96.

[12] Boheim, R., and M. Taylor (2002): "Tied Down or Room to Move? Investigating the Relationships between Housing Tenure, Employment Status and Residential Mobility in Britain", Scottish Journal of Political Economy, 49, 369-392.

[13] Bohra-Mishra, P., and D. Massey (2011): "Individual Decisions to Migrate During Civil Conflict", Demography, 48, 401-424.

[14] Bollen, K. (1989): "Structural Equations with Latent Variables", John Wiley \& Sons, Inc.

[15] Borjas, G. (1999): "Immigration and Welfare Magnets", Journal of Labor Economics, 17(4), 607-637. 
[16] Cameron, A.C., and P.K. Trivedi (2005): "Microeconometrics: Methods and Applications", Cambridge University Press.

[17] Clark, A. (2001): "What Really Matters in a Job? Hedonic Measurement Using Quit Data", Labour Economics, 8, 223-242.

[18] Clark, A., E. Diener, Y. Georgellis, and R. Lucas (2008): "Lags and Leads in Life Satisfaction: a Test of the Baseline Hypothesis", Economic Journal, 118, 222-243.

[19] De Jong, G., R. Abad, B. Carino, J. Fawcett, and R. Gardner (1983): "International and Internal Migration Decision Making: a Value-Expectancy Based Analytical Framework of Intensions to Move from a Rural Philippine Province", International Migration Review, 17(3), 470-484.

[20] De Jong, G., A. Chamratrithirong, and Q. Tran (2002): "For Better, for Worse: Life Satisfaction Consequences of Migration", International Migration Review, $36(3), 838-863$.

[21] De Neve, J., N. Christakis, J. Fowler, and B. Frey (2011): "Genes, Economics, and Happiness", mimeo.

[22] Di Tella, R., J. Haisken-De New, and R. MacCulloch (2010): "Happiness Adaptation to Income and to Status in an Individual Panel", Journal of Economic Behavior and Organization, 76, 834-852.

[23] Diener, E., E. Suh, R. Lucas, and H. Smith (1999): "Subjective Well-Being: Three Decades of Progress", Psychological Bulletin, 125(2), 276-302.

[24] Dolan, P., and D. Kahneman (2008): "Interpretations of Utility and Their Implications for the Valuation of Health", Economic Journal, 118, 215-234.

[25] Dreher, A., Krieger, T., and D. Meierrieks (2011): "Hit and (They Will) Run: The Impact of Terrorism on Migration", Economics Letters, 113, 42-46.

[26] Dustmann, C. (2003): "Children and Return Migration", Journal of Population Economics, 16, 815-830.

[27] Dustmann, C., F. Fabbri, and I. Preston (2005): "The Impact of Immigration on the British Labour Market", Economic Journal, 115, 324-341.

[28] Dustmann, C., T. Hatton, and I. Preston (2005): "The Labour Market Effects of Immigration", Economic Journal, 115, 297-299.

[29] Easterlin, R., and A. Zimmermann (2008): "Life Satisfaction and Economic Outcomes in Germany Pre- and Post-Unification", Journal of Economic Behavior and Organization, 68 (3-4), 433-444.

[30] Freeman, R. (1978): "Job Satisfaction as an Economic Variable", American Economic Review, 68(2), 135-141.

[31] Frey, B., and A. Stutzer (2002): "What Can Economists Learn from Happiness Research?" Journal of Economic Literature, 40(2), 402-435. 
[32] Frey, B., and A. Stutzer (2006): "Does Marriage Make People Happy, or Do Happy People Get Married?" Journal of Socio-Economics, 35, 326-347.

[33] Gibson, J., and D. McKenzie (2011): "The Microeconomic Determinants of Emigration and Return Migration of the Best and Brightest: Evidence from the Pacific", Journal of Development Economics, 95(1), 18-29.

[34] Gordon, I., and I. Molho (1995): "Duration Dependence in Migration Behavior: Cumulative Inertia versus Stochastic Change", Environment and Planning, 27, 1961-1975.

[35] Greenwood, M.(1997): "Internal Migration in Developed Countries". In Rosenzweig, M. and O. Stark (eds.) Handbook of Population and Family Economics, Ch.12, Vol. 1B, North Holland.

[36] Guven, C. (2012): "Reversing the Question: Does Happiness Affect Consumption and Savings Behavior?", Journal of Economic Psychology, 33, 701-717.

[37] Guven, C., C. Senik, and H. Stichnoth (2012): "You Can’t Be Happier Than Your Wife. Happiness Gaps and Divorce", Journal of Economic Behavior and Organization, 82(1), 110-130.

[38] Hale, J. and B. Householder (2002): "The Theory of Reasoned Action." In J. Dillard and M. Pfau (Eds.), The Persuasion Handbook: Developments in Theory and Practice, Newbury Park: CA Sage, 259-286.

[39] Kahneman, D., P. Wakker, and R. Sarin (1997): "Back to Bentham? Explorations of Experienced Utility", Quarterly Journal of Economics, 112(2), 375-405.

[40] Kaufmann, D., A. Kraay, and M. Mastruzzi (2009): "Governance Matters VIII: Governance Indicators for 1996-2008". World Bank Policy Research Working Paper \#4978.

[41] Kennan, J., and J. Walker (2011): "The Effect of Expected Income on Individual Migration Decisions", Econometrica, 79(1), 211-251.

[42] Kristensen, N., and N. Westergerd-Nielsen (2004): "Does Low Job Satisfaction Lead to Job Mobility?" IZA Discussion Paper No. 1026.

[43] Lucas, R., A. Clark, Y. Georgellis, and E. Diener (2003): "Reexamining Adaptation and the Set Point Model of Happiness: Reactions to Changes in Marital Status", Journal of Personality and Social Psychology, 84(3), 527-539.

[44] Lucas, R., A. Clark, Y. Georgellis, and E. Diener (2004): "Unemployment Alters the Set Point for Life Satisfaction", Psychological Science, 15(1), 8-13.

[45] Lyubomirsky, S., L. King, and E. Diener (2005): "The Benefits of Frequent Positive Affect: Does Happiness Lead to Success?", Psychological Bulletin, 131(6), 803-855.

[46] Lyubomirsky, S., K. Sheldon, and D. Schkade (2005): "Pursuing Happiness: The Architecture of Sustainable Change", Review of General Psychology, 9(2), 111-131. 
[47] Morrison, A. (1993): "Violence or Economics: What Drives Internal Migration in Guatemala?" Economic Development and Cultural Change, 41(4), 817-831.

[48] Rabinovich, A., and P. Webley (2007): "Filling the Gap between Planning and Doing: Psychological Factors Involved in the Successful Implementation of Saving Intention", Journal of Economic Psychology, 28(4), 444-461.

[49] Raudenbush, S. , and A. Bryk (2002): "Hierarchical Linear Models", 2nd ed., Thousand Oaks: Sage.

[50] Safi, M. (2010): "Immigrants' Life Satisfaction in Europe: Between Assimilation and Discrimination", European Sociological Review, 26(2), 159-176.

[51] Shields, M., and M. Ward (2001): "Improving Nurse Retention in the National Health Service in England: the Impact of Job Satisfaction on Intentions to Quit", Journal of Health Economics, 20, 677-701.

[52] Sirkeci, I. (2005): "War in Iraq: Environment of Insecurity and International Migration", International Migration, 43(4), 197-214.

[53] Sjaastad, L. (1962): "The Costs and Returns of Human Migration", Journal of Political Economy, 70(5), 80-93.

[54] Stark, O. (2003): "Tales of Migration without Wage Differentials: Individual, Family, and Community Contexts", ZEF Discussion Paper No.73.

[55] Stark, O. (2006): "Inequality and Migration: A Behavioral Link", Economics Letters, 96, 146-152.

[56] Stark, O., and D. Bloom (1985): "The New Economics of Labor Migration", American Economic Review, 75(2), 173-178.

[57] Stark, O., and J. Taylor (1991): "Migration Incentives, Migration Types: the Role of Relative Deprivation", Economic Journal, 101, 1163-1178.

[58] Stark, O., and Y. Wang (2000): "A Theory of Migration as a Response to Relative Deprivation", German Economic Review, 1(2), 131-143.

[59] Stevens, P. (2005): "The Job Satisfaction of English Academics and Their Intentions to Quit Academe", NIESR Discussion Paper No. 262.

[60] Tiebout, C. (1956): "A Pure Theory of Local Expenditures", Journal of Political Economy, 64 (5), 416-424.

[61] Vlaev, I. (2012): "How Different are Real and Hypothetical Decisions? Overestimation, Contrast and Assimilation in Social Interaction", Journal of Economic Psychology, 33, 963-972. 


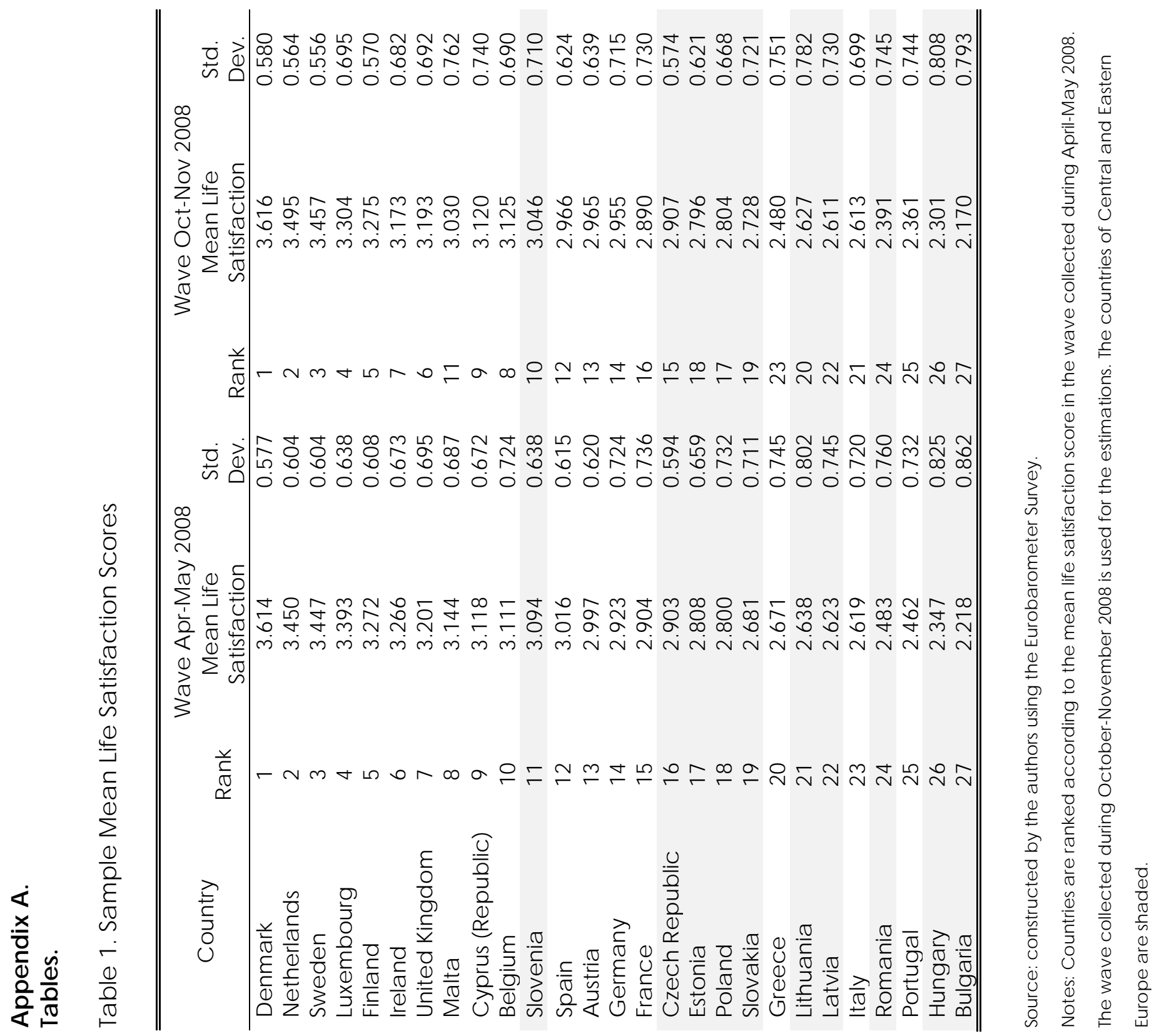




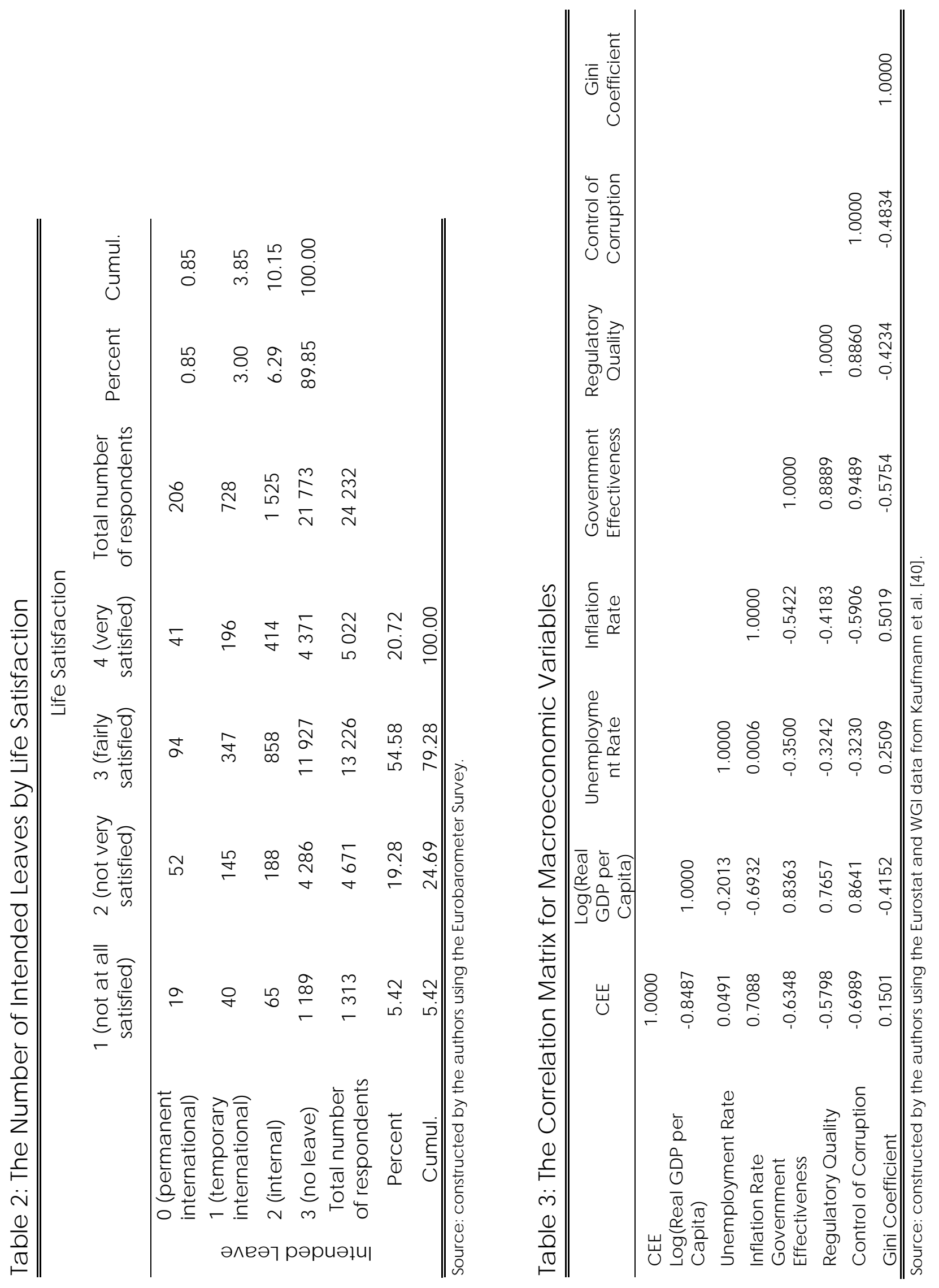




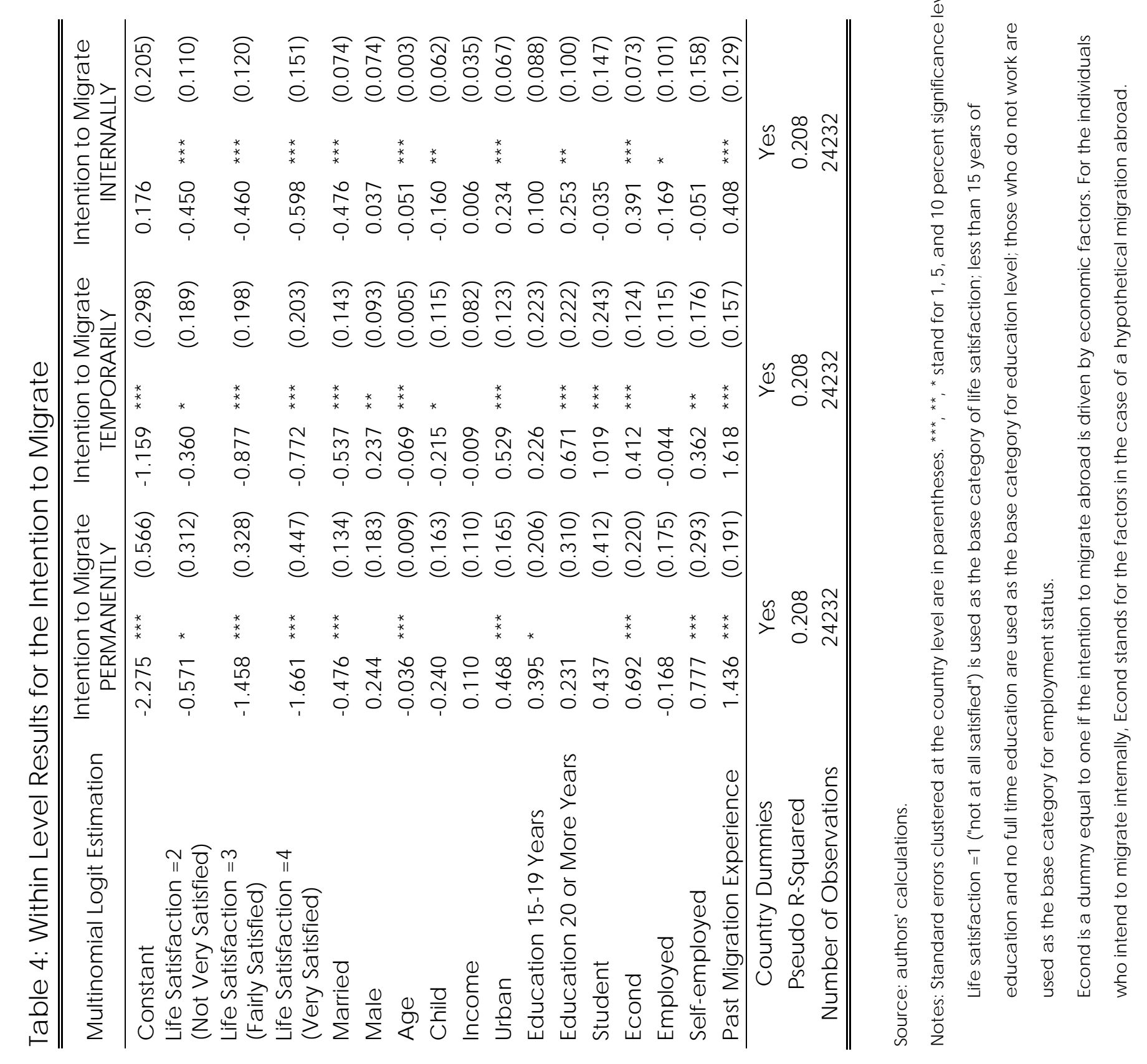




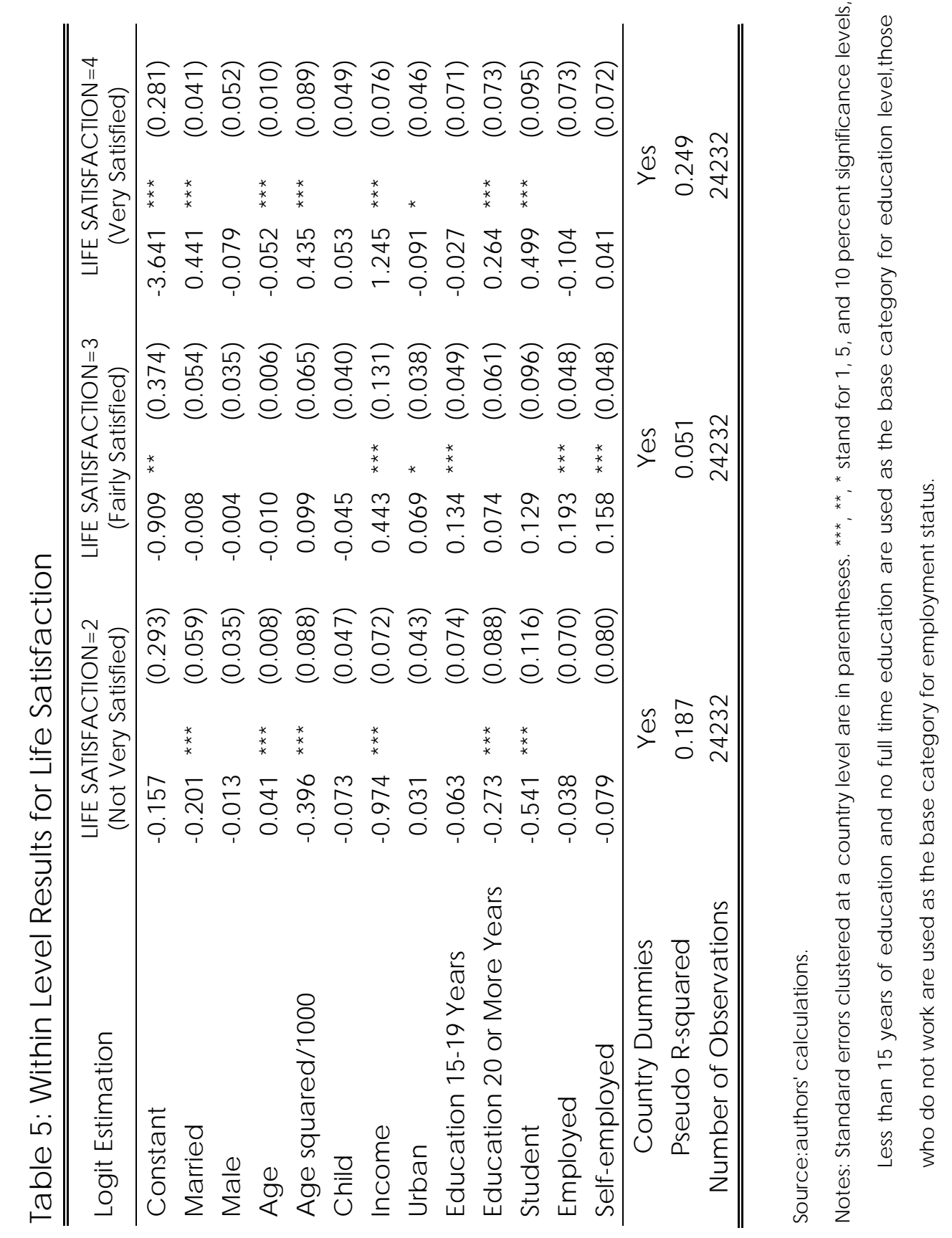




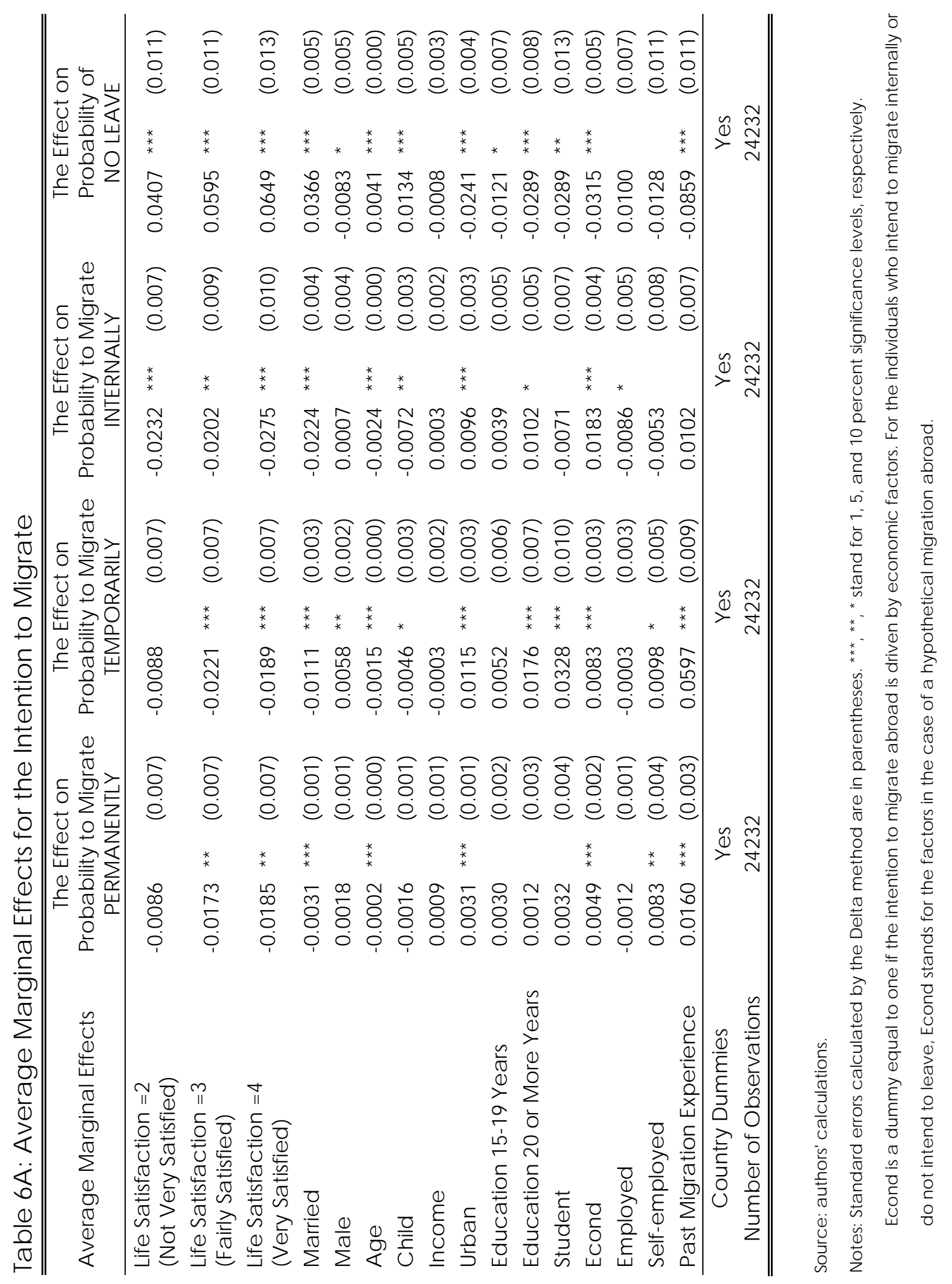




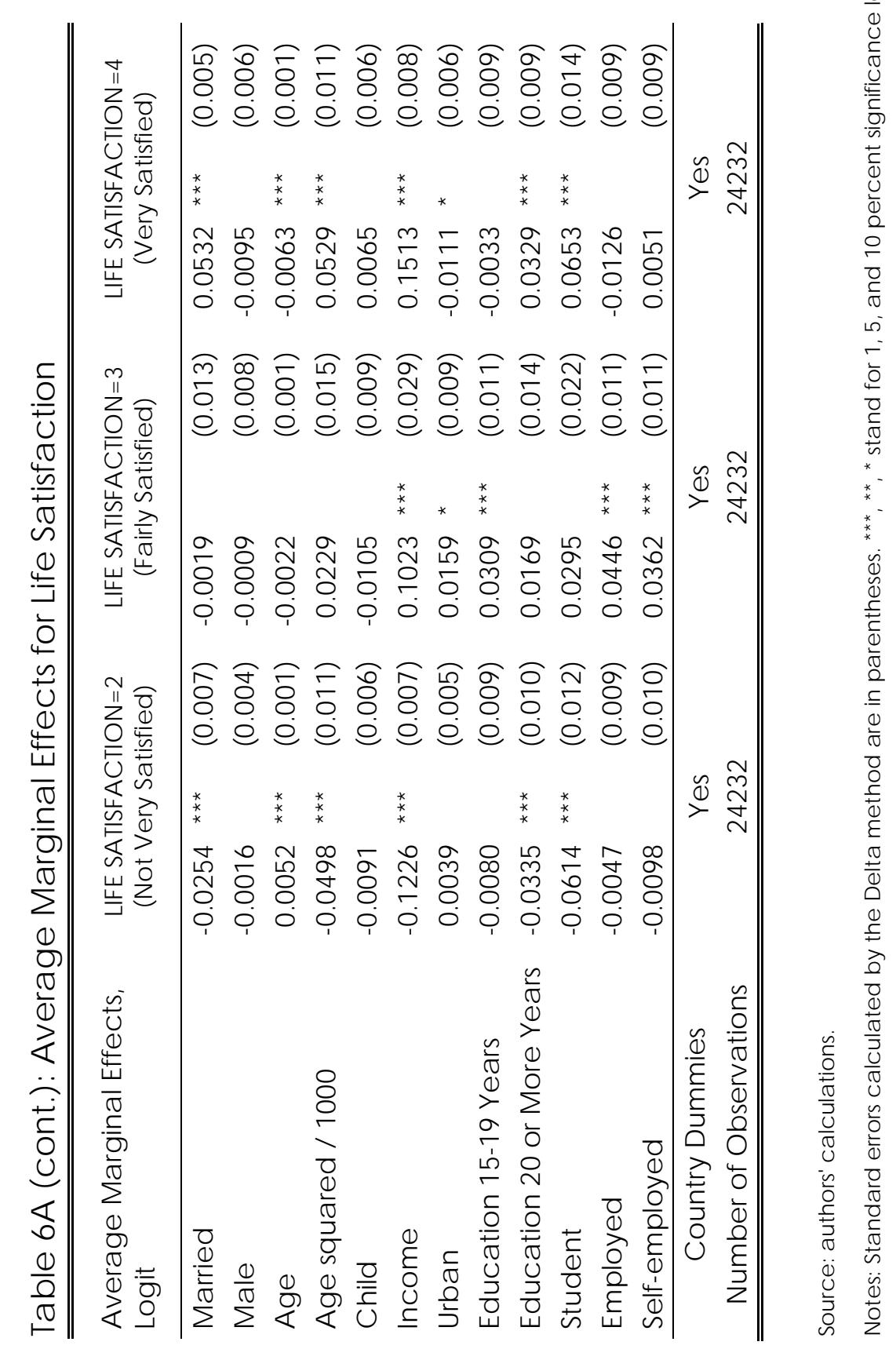




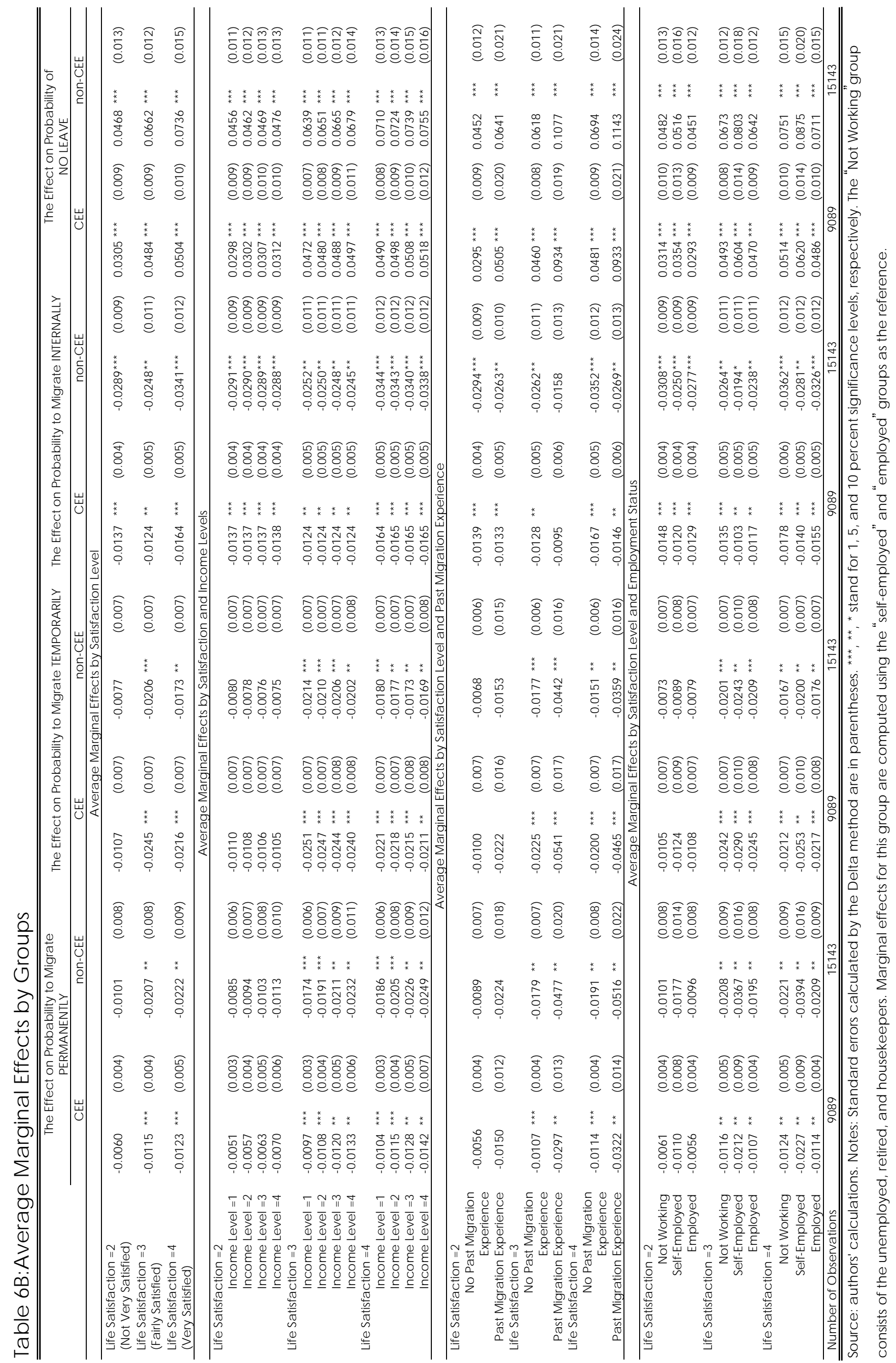




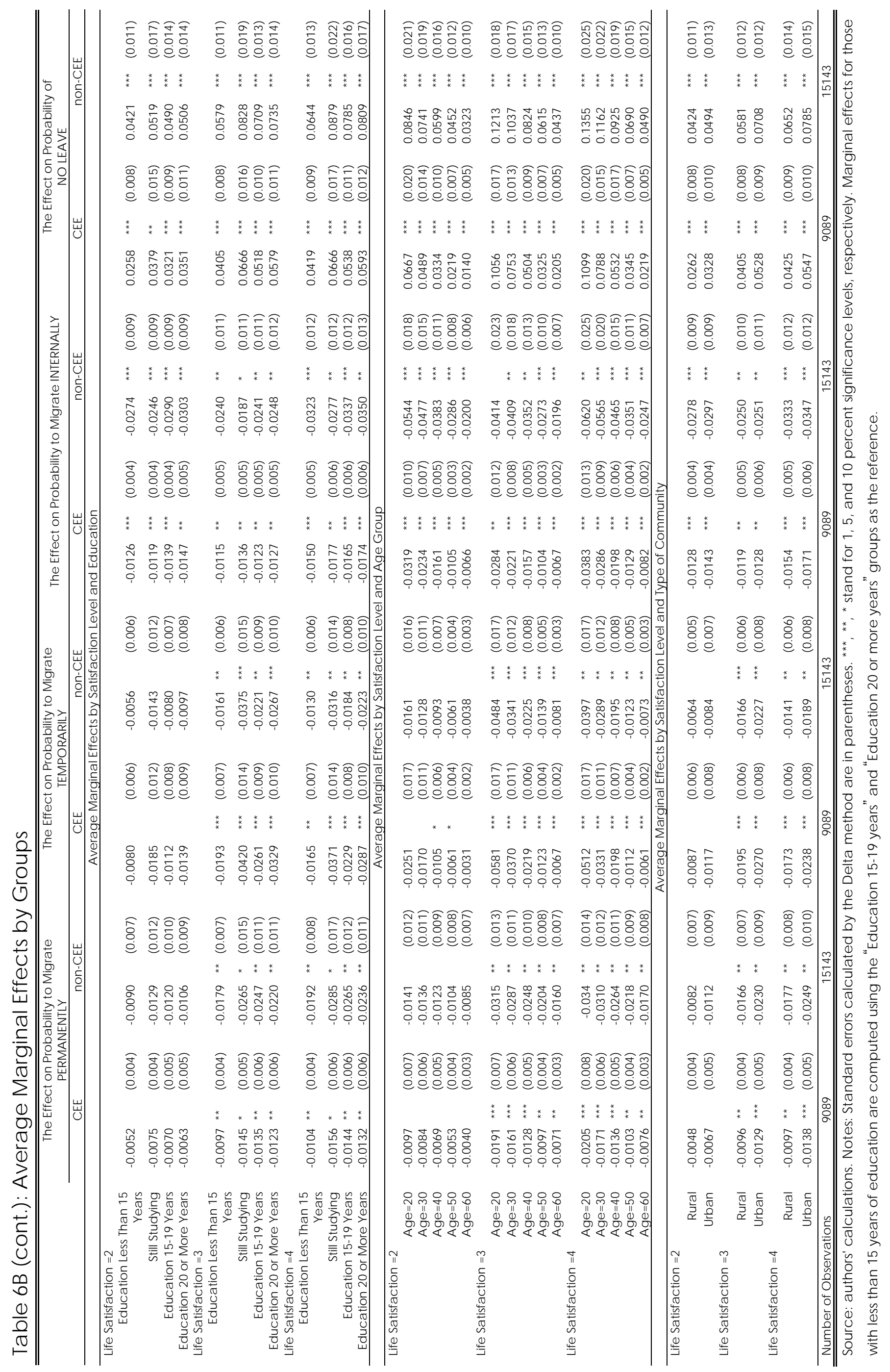




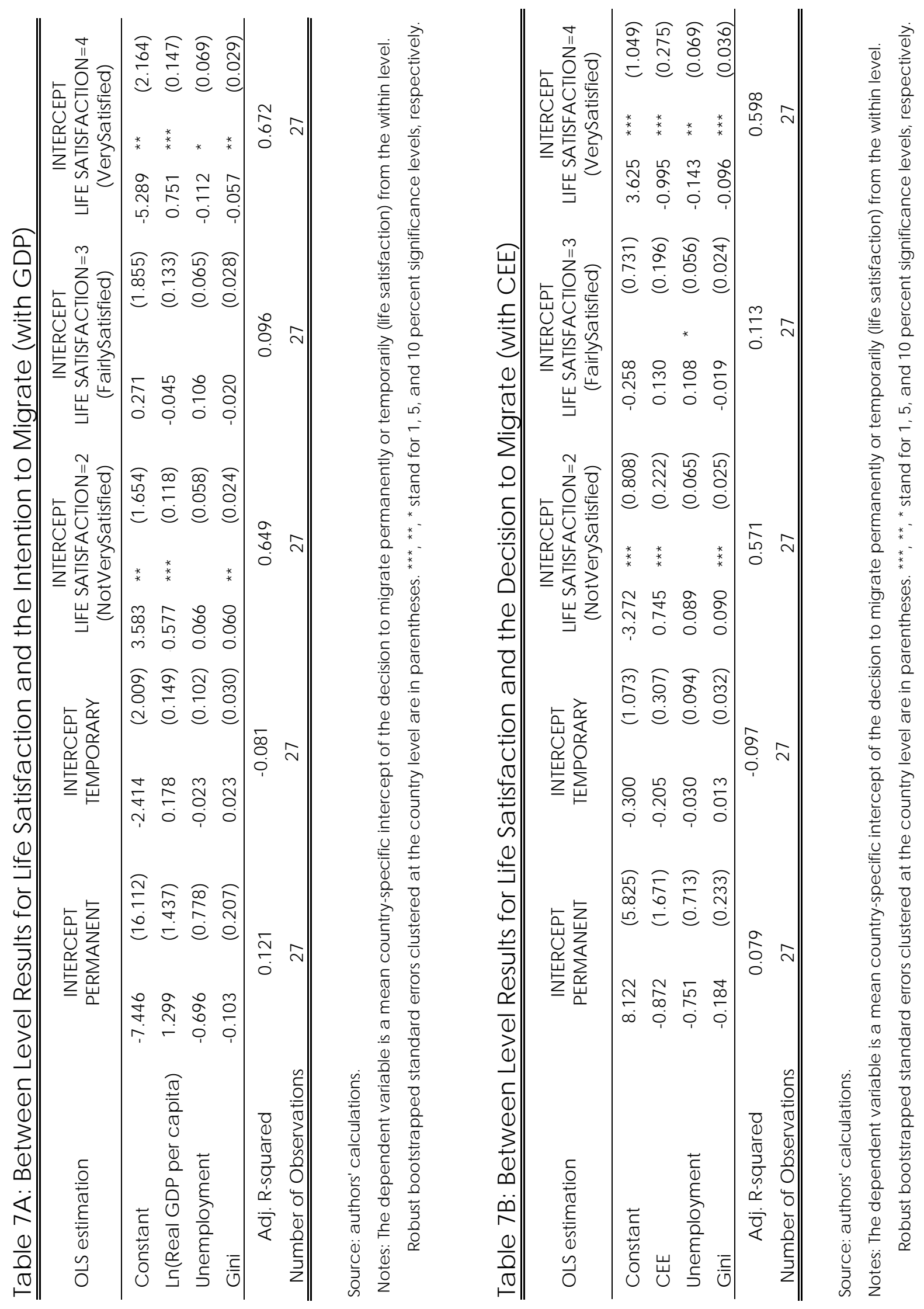




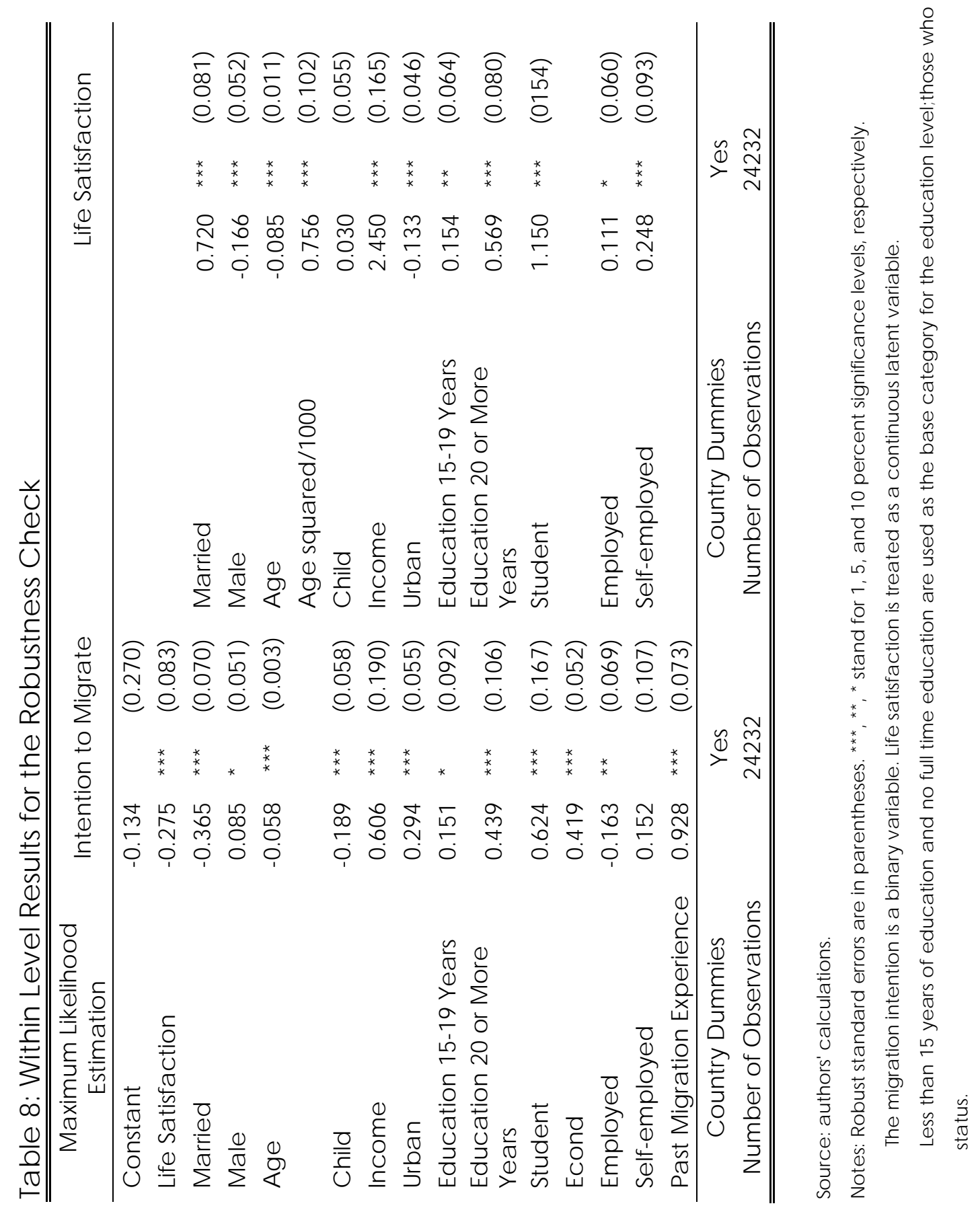




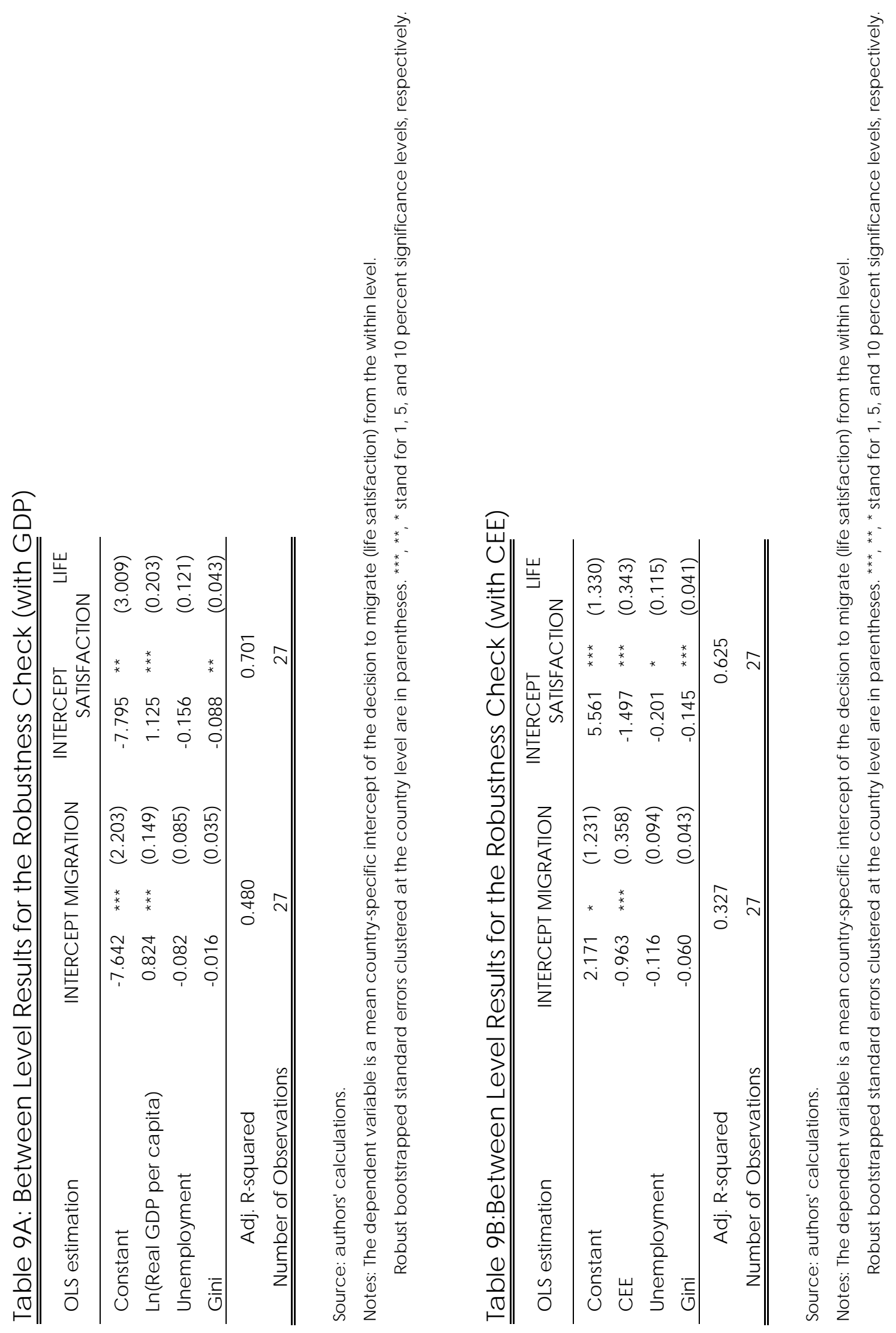




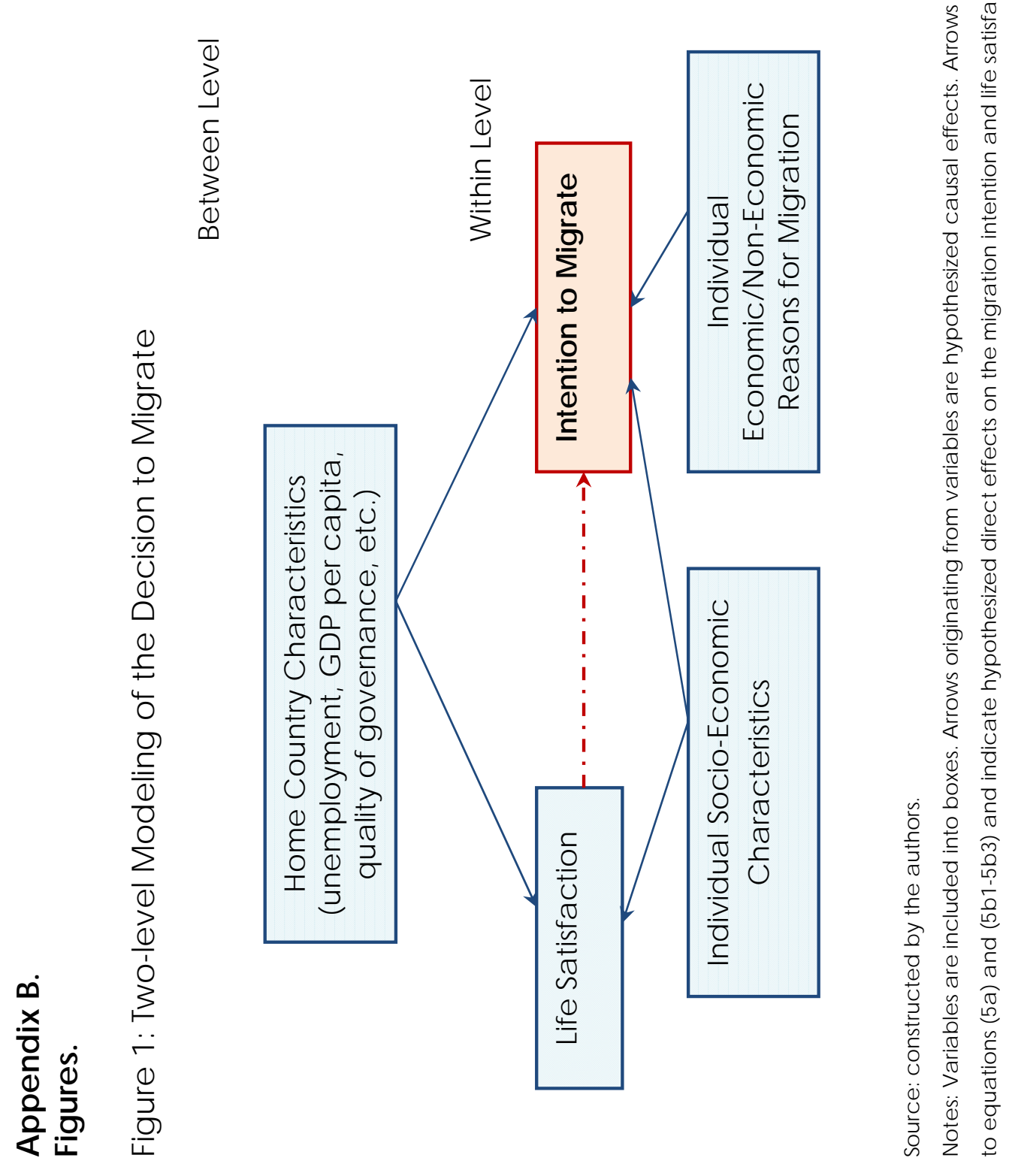


